\title{
Dietary patterns and difficulty conceiving: a nested case-control study
}

\author{
Estefania Toledo ${ }^{\mathrm{a}}$ \\ Cristina López-del Burgo ${ }^{\mathrm{a}, \mathrm{b}}$ \\ Alvaro Ruiz-Zambrana ${ }^{\mathrm{c}}$ \\ Mikel Donazar ${ }^{\mathrm{d}}$ \\ Íñigo Navarro-Blasco ${ }^{\mathrm{e}}$ \\ Miguel A. Martínez-González ${ }^{\text {a }}$ \\ Jokin de Irala ${ }^{a, b}$
}
a Department of Preventive Medicine and Public Health, University of Navarra, Pamplona, Navarra, Spain
c Department of Obstetrics and Gynecology, University of Navarra, Pamplona, Navarra, Spain
${ }^{\mathrm{d}}$ School of Medicine, University of Navarra, Pamplona, Navarra, Spain
${ }^{\mathrm{b}}$ Institute for Culture and Society, University of Navarra, Pamplona, Navarra, Spain
e Department of Chemistry and Soil Science, School of Science, University of Navarra, Pamplona, Navarra, Spain
*Corresponding author:

Tel: +34 948425600 (ext.6224) Fax: +34 948425649

E-mail address: etoledo@unav.es

\section{Published in: \\ Fertility and Sterility \\ (http://www.fertstert.org/)}

See original article in the Journal's web page:

http://www.sciencedirect.com/science/article/pii/S001502821102485X\#ref bib4

\section{Cite as:}

Toledo E, López-del Burgo C, Ruiz-Zambrana A, Donazar M, Navarro-Blasco I, Martínez-Gonzalez M.A., De Irala J. Dietary patterns and difficulty conceiving: a nested case-control study. Fertility and Sterility 2011;96:1149-1153. 


\begin{abstract}
Objective: To investigate potential associations between dietary patterns (defined using factor analysis) and difficulty conceiving.
\end{abstract}

Design: Case-control study nested in a Spanish cohort of university graduates (Seguimiento Universidad de Navarra [SUN] Project).

Setting: Female university graduates all over Spain participating in the SUN Project.

Patient(s): A total of 485 women, aged 20-45 years, reporting having presented with difficulty getting pregnant, and 1,669 age-matched controls who had at least one child.

Intervention(s): None.

Main Outcome Measure(s): Reported difficulty getting pregnant. Data were collected from baseline and follow-up questionnaires of the SUN Project.

Results: Two dietary patterns were identified. They were labeled as "Mediterraneantype" and "Western-type" patterns. A lower risk of difficulty getting pregnant was apparent in the highest quartile of adherence to the Mediterranean-type pattern compared with the lowest quartile (odds ratio $0.56,95 \%$ confidence interval $0.35-0.95$ ). Greater adherence to the Western-type dietary pattern showed no association with this outcome.

Conclusion: A greater adherence to the Mediterranean-type dietary pattern may enhance fertility. Further evidence about the relationship between this dietary pattern and fertility is needed to develop nutritional interventions for women desiring to get pregnant. 
Key Words: Dietary pattern; difficulty getting pregnant; principal component analysis; diet; Mediterranean; dietary pattern; Western

\section{Introduction}

Infertility prevalence rates range from $3.5 \%$ to $16.7 \%$ in developed nations and from $6.9 \%$ to $9.3 \%$ in developing nations(1). Infertility is defined as the failure to achieve a clinical pregnancy after 12 months or more of regular unprotected sexual intercourse $(2$, $3)$.

There are multiple causes of infertility, including ovulatory disorders, endometriosis, tubal or uterine abnormalities, cervical or sperm factors, or even psychological problems, among others. Modifiable lifestyle factors, such as diet, smoking, physical activity, and caffeine or alcohol consumption, may also affect fertility (4).

With respect to diet, several studies have found associations between a high consumption of low-fat dairy food, animal proteins, trans unsaturated fats, and carbohydrates, as well as high dietary glycemic load, and ovulatory infertility (5-8). All these findings suggest that insulin and glucose metabolism may affect fertility. Increased insulin resistance, present among women with diabetes, polycystic ovary syndrome, high body weight, or decreased physical activity, seems to lead to ovulatory dysfunction $(9,10)$. However, more studies are needed to verify the role of the abovementioned dietary factors on ovulatory infertility in other populations.

Some additional evidence is nonetheless available; a prospective cohort study conducted in the Netherlands found a preconceptional Mediterranean-type diet to be associated with a $40 \%$ increased probability of success in achieving pregnancy among couples undergoing IVF. Among other explanations, the authors suggested that this 
benefit could be partly mediated by the high intake of vegetable oils in the Mediterranean-type diet, especially linoleic acid. This fatty acid is a precursor of the prostaglandins that play an important role in the ovulatory cycle and endometrial receptivity (11).

The benefits of the Mediterranean-type diet on health have been well-publicized. It is associated with a significant reduction of overall mortality, cardiovascular disease, and cancer incidence and mortality, as well as the incidence of neurodegenerative diseases (12). Adherence to the Mediterranean-type diet also seems to reduce the risk of weight gain and diabetes $(13,14)$, conditions that raise insulin resistance and may thus lead to ovulatory infertility. However, studies that specifically evaluate the effects of the Mediterranean-type diet on fertility are scarce.

Greater scientific knowledge about modifiable dietary risk factors would enable specific recommendations, mainly based on nutritional changes, to be given to some couples that are unable to achieve a pregnancy.

The objective of this study was to investigate associations between the main dietary patterns of a cohort of university graduates (the SUN [Seguimiento Universidad de Navarra] Project) and the experience of difficulty getting pregnant.

\section{Materials and methods}

\section{Study Population}

This study was conducted within the framework of the SUN Project, whose methods have been described in detail elsewhere (15). Briefly, the SUN Project is an ongoing, dynamic, multipurpose prospective cohort of university graduates all over Spain that started in December 1999. To date the SUN Project has recruited more than 20,000 
participants, of whom 12,350 are women; it has an approximate retention rate of $90 \%$. Participants are contacted biennially through mailed questionnaires about lifestyle factors and health outcomes such as difficulty getting pregnant, cardiovascular disease, and cancer, among others. To allow for a minimum follow-up of 2 years and a lag-time period of 9 months, only 10,977 women recruited before July 31, 2007 were considered for the present analysis. Of these women, 8,619 were aged 20-45 years at study entrance. Information on follow-up was available for 7,763 of these women.

Women answering affirmatively the question, "Have you consulted a physician because of difficulty getting pregnant?” during follow-up were considered as cases. Six hundred fifteen women met this criterion. These cases were matched with a variable number of controls who were women of the same age and time participating in the cohort but who had at least one child. All cases and their matched controls were combined into a single stratum for the analyses. Because of the availability of appropriate controls, we had 567 cases and 1,950 controls. After excluding women with extreme total caloric intakes (defined as $<500$ or $>3,500 \mathrm{kcal} / \mathrm{d})(\mathrm{n}=282)$ and women with missing values on important covariates $(n=94)$, our effective sample comprised 485 cases and 1,669 matched controls. Given the observed number of women who reported having consulted for difficulty getting pregnant and the number of controls per case, our statistical power was $90 \%$ assuming an a priori rate of difficulty getting pregnant of $10 \%$ (1) and an expected odds ratio of 0.5 assuming a two-tailed $\alpha$ error of 0.05 (9).

The present study was approved by the institutional review board of the University of Navarra, and the participant's voluntary completion of the baseline questionnaire constituted informed consent. 


\section{Assessment of Dietary Variables}

Information on diet was collected from a previously validated 136-item food-frequency questionnaire at baseline $(16,17)$. Each item included a typical portion size, and consumption frequencies were gathered in nine categories (six or more times per day; four to six times per day; two to three times per day; once daily; five to six times per week; two to four times per week; once weekly; one to three times per month; never or seldom). Daily food consumption was calculated by multiplying typical portion sizes by consumption frequency for each food item. The nutrient composition of dietary intake was derived from Spanish food composition tables $(18,19)$.

Consumption patterns for the 136 food items, first obtained by the food-frequency questionnaire and then transformed into grams per day, were grouped into 30 predefined food categories (20). We performed a principal component analysis to identify the main dietary patterns of the participants in the SUN Project. A scree plot test was conducted to determine the number of factors to be extracted. Factors were rotated with an orthogonal rotation procedure (varimax rotation). Consequently, our factors were not correlated to each other. Food group loadings $>0.30$ were considered relevant components of the dietary patterns. Considering the observed weights of the food groups in the different dietary patterns, we named the first factor "Western-type dietary pattern" (WDP) and the second "Mediterranean-type dietary pattern" (MedDP) (21). We obtained the score for each participant by summing the consumption of each food group weighted by the correlation coefficient of each factor score. The obtained quantitative score was then categorized into quartiles. 


\section{Assessment of Nondietary Variables}

Information on age, weight, height, and smoking status was obtained through the baseline questionnaire. Body mass index was calculated as weight (in kilograms) divided by the square of height in meters (22). Information on physical activity was gathered with a previously validated questionnaire (23) that addressed time spent in 17 different sport activities. The time spent in each activity was multiplied by a multiple of the resting metabolic rate according to previously published guidelines (24).

Questionnaires used in the SUN project are available on the Web page www.unav.es/sun/.

\section{Statistical Analysis}

Participants were classified according to quartiles of adherence to the a posterioriidentified dietary patterns. Plant and animal protein intake, as well as trans fat and fiber intake, were adjusted for total energy intake according to the residual method (25).

Because of the matched design of our study, we fitted conditional logistic regression models to evaluate associations between adhering to a MedDP or WDP and consulting a physician because of difficulties getting pregnant. We present matched models without any further adjustment and three adjusted models that take into account several variables. Model 1 included the number of children. Model 2, the number of children as well as the following variables: body mass index (categorized as $<25,25$ to $<30$, and $\geq 30 \mathrm{~kg} / \mathrm{m}^{2}$ ), smoking status (never, past, current), alcohol consumption (grams per day), total energy intake (categorized into quartiles), use of vitamin supplements (yes/no). Model 3 included all the factors in model 2 and intake of plant proteins (grams per day), intake of animal proteins (grams per day), intake of trans fat (grams per day), and intake of fiber (grams per day). 
To assess the linear trend tests, quartile-specific medians were assigned to each quartile, and the resulting variable was treated as quantitative.

Finally, to examine the contribution of the 30 defined food groups on the difficulty conceiving, we also fit conditional regression models considering each of the 30 food groups (approximate quartiles) as independent variables. Taking into account the issue of multiple comparisons, the Benjamini-Hochberg rule was applied (26).

Variance inflation factors were calculated to reassure that there were no multicollinearity problems in the fully adjusted models (27).

All $P$ values were two-tailed and were calculated with the log-likelihood ratio test. Statistical significance was set a priori at $P<.05$. Analyses were preformed with the SPSS statistical software package, version 15.0.

\section{Results}

Baseline characteristics of the 485 cases and 1,669 paired controls are displayed in Table 1. Cases had fewer children and tended to use vitamin supplements less frequently.

The principal component analysis yielded general dietary patterns (Table 2) that explained $19 \%$ of the total food consumption variability. Factor loadings for the two identified dietary patterns are presented in Table 2 . The first vector is characterized by a high consumption of processed and unprocessed red meat, fast food, whole-fat dairy products, commercial bakery, potatoes, eggs, refined grains, sauces, processed meals, and sugar-sweetened soda. The second vector consisted of a high consumption of vegetables, fish, fruits, poultry, low-fat dairy products, and olive oil. Thus, we named 
these two vectors as the "Western-type dietary pattern" and the "Mediterranean-type dietary pattern.”

There was no statistically significant association between having a WDP and consulting a physician because of difficulty getting pregnant (Table 3).

Within the MedDP, on the other hand, there were statistically significant lower odds of consulting a physician because of difficulty getting pregnant among women with the highest adherence to the MedDP (fourth quartile) compared with those with the lowest adherence (Table 4). This association remained statistically significant even after adjusting for multiple comparison according to the Benjamini-Hochberg rule (26).

Results after the exclusion of women with total caloric intake between 500 and 1,000 $\mathrm{kcal} / \mathrm{d}$ were practically identical.

When we assessed the association between each of the 30 food groups and difficulty conceiving, a statistically significant direct association was apparent for the consumption of alcoholic beverages, whereas an inverse association was found for poultry consumption (available upon request).

All variance inflation factors of the fully adjusted models were $<3.2$.

\section{Discussion}

In this matched nested case-control study, greater adherence to a Mediterranean-type dietary pattern was associated with a lower risk of consulting a physician because of difficulty getting pregnant. On the other hand, adherence to the Western-type dietary pattern, unlike greater adherence to a MedDP, does not seem to be associated with any harm or protection against this problem. 
Several dietary factors have been associated with the risk of subfertility $(5-8,28,29)$. From a macronutrient perspective, greater intake of carbohydrates in place of naturally occurring fats was associated with an increased risk of ovulatory infertility in a large cohort of married premenopausal women in the Nurses' Health Study (8). Among the same women, higher protein intake was associated with an increased risk of ovulatory infertility (7). This latter association was mainly driven by animal protein intake, which showed a direct association with ovulatory infertility, whereas the association of vegetable protein with the same outcome was not statistically significant. Finally, no clear association between fat intake and ovulatory infertility was observed in the Nurses' Health Study (6). However, higher intake of trans unsaturated fat instead of carbohydrates was associated with an increased risk of ovulatory infertility. Furthermore, in women with a high iron intake, polyunsaturated fatty acids showed a statistically significant lower risk of ovulatory infertility.

With respect to micronutrient intake, there is no conclusive evidence concerning the role of specific micronutrients on fertility and birth outcomes (28), except for the association between periconceptional folic acid and neural tube defects. Nonetheless, the Nurses' Health Study found that regular use of multivitamin supplements was associated with a lower risk of ovulatory infertility (29), thus suggesting that improving micronutrient intake may enhance female fertility. This association was partially explained by the B vitamins, particularly folic acid.

Another means of approaching the association between dietary factors and health outcomes is to consider individual food items or food groups in more detail. The association between dairy products, for example, and ovulatory infertility was addressed in the Nurses' Health Study (5). In fact, Chavarro et al. observed a differential effect of 
low-fat and whole-fat dairy products. Whereas the former were directly associated with a risk of ovulatory infertility, the latter showed an inverse and protective relationship. It is usual in nutritional epidemiology to observe that overall food patterns have a greater biological effect than individual foods. In this context, we did not find any association between food groups and difficulty conceiving, with the exception of poultry. The observed association between alcoholic beverages and difficulty getting pregnant deserves further attention.

A more comprehensive approach to investigate the associations between dietary factors and health outcomes is to assess the impact of the overall diet rather than separate foods or nutrients (30). This approach is considered to more closely resemble the reality of community-dwelling subjects, for whom nutrients are not consumed individually but are simply found in commonly consumed foods. The various potential interactions between general foods and specific nutrients therefore have to be taken into account.

Evidence concerning the association between dietary patterns and fertility is scarce. Chavarro et al. (9), however, drawing upon their previous findings linking dietary factors to infertility, developed a diet score defined by its conformity to several key factors: high monounsaturated trans fatty acid intake, the consumption of vegetables rather than meat as a protein source, low glycemic carbohydrates, whole-fat dairy products, multivitamins, and iron from plants and supplements. They found that this fertility diet was associated with a $69 \%$ lower risk of ovulatory disorder infertility. The significance of this finding notwithstanding, this dietary pattern was specifically constructed on the basis of their previous observations and may thus not fully capture actual dietary patterns from ordinary women in most communities. 
The principal component analysis was also used to identify main dietary patterns in a Dutch cohort of couples seeking to conceive by means of IVF or intracytoplasmic sperm injection (11). As in our study, the authors labeled as a Mediterranean-type dietary pattern one of the vectors they found in factor analysis and observed that higher adherence to this dietary pattern before conception was associated with a higher probability of pregnancy. These results are also consistent with our findings. It is noteworthy that other than in the Dutch study, our data stemmed from an actual Mediterranean-type country.

We acknowledge that our study has some limitations, such as the fact that the principal component analysis we used tends to emphasize sample-specific factors. Nevertheless, similar dietary patterns have been identified in very different samples, such as participants of the Spanish European Prospective Investigation into Cancer and Nutrition (31); this suggests that the dietary patterns we identified are representative of the majority of the Spanish population. Second, the self-reported outcomes by the female participants of our cohort would tend to lead to a nondifferential misclassification, which would in turn shift the results toward the null. Misreporting seems unlikely, however, owing to the high educational level of our participants (all university graduates). In fact, other self-reported diagnoses and health-related issues (e.g., hypertension, metabolic syndrome, depression, weight, and physical activity) have been validated in our cohort to show a high degree of accuracy $(22,23,32-34)$. In addition, participants who reported having consulted a physician because of difficulty getting pregnant had a mean of 0.2 children, compared with 1.2 for control women. This confirms the lower fecundity among women reporting difficulties getting pregnant in the SUN cohort. Finally, several causes of difficulty getting pregnant could be considered together in our composed outcome. This would also tend to lead to a 
nondifferential misclassification, which would shift the results toward the null. Despite the discussed limitations, the fact that this case-control study is nested within a large prospective cohort of university graduates merits being highlighted as an outstanding strength.

In conclusion, our results suggest that greater adherence to a Mediterranean-type diet may enhance fertility. Further studies are needed to confirm the protective role of a Mediterranean-type diet on difficulty getting pregnant. Reliable evidence concerning the relationship between diet and fertility is crucial for developing nutritional interventions and guidelines for women of reproductive age interested in getting pregnant. The Mediterranean-type diet seems to be an efficient and healthy alternative means of enhancing fertility.

\section{Acknowledgments}

The authors thank participants of the SUN project for their continued cooperation; all members of the SUN project group for their administrative, technical, and material support; and Matthew Hanley for editing and proofreading the manuscript.

\section{Disclosure of interests}

E.T. has nothing to disclose. C.L.-d.B. has nothing to disclose. A.R.-Z. has nothing to disclose. M.D. has nothing to disclose. Í.N.-B. has nothing to disclose. M.A.M.-G. has nothing to disclose. J.d.I. has nothing to disclose. 


\section{References}

1. J. Boivin, L. Bunting, J.A. Collins and K.G. Nygren, International estimates of infertility prevalence and treatment-seeking: potential need and demand for infertility medical care. Hum Reprod, 22 (2007), pp. 1506-1512.

2. American Society for Reproductive Medicine, Definitions of infertility and recurrent pregnancy loss. Fertil Steril, 90 (2008), p. S60.

3. F. Zegers-Hochschild, G.D. Adamson, J. de Mouzon, O. Ishihara, R. Mansour and K. Nygren, et al. International Committee for Monitoring Assisted Reproductive Technology (ICMART) and the World Health Organization (WHO) revised glossary of ART terminology, 2009. Fertil Steril, 92 (2009), pp. 1520-1524.

4. G.F. Homan, M. Davies and R. Norman, The impact of lifestyle factors on reproductive performance in the general population and those undergoing infertility treatment: a review. Hum Reprod Update, 13 (2007), pp. 209-223.

5. J.E. Chavarro, J.W. Rich-Edwards, B. Rosner and W.C. Willett, A prospective study of dairy foods intake and anovulatory infertility. Hum Reprod, 22 (2007), pp. 13401347.

6. J.E. Chavarro, J.W. Rich-Edwards, B.A. Rosner and W.C. Willett, Dietary fatty acid intakes and the risk of ovulatory infertility. Am J Clin Nutr, 85 (2007), pp. 231-237.

7. J.E. Chavarro, J.W. Rich-Edwards, B.A. Rosner and W.C. Willett, Protein intake and ovulatory infertility, . Am J Obstet Gynecol, 198 (2008) 210.e1-7.

8. J.E. Chavarro, J.W. Rich-Edwards, B.A. Rosner and W.C. Willett, A prospective study of dietary carbohydrate quantity and quality in relation to risk of ovulatory infertility. Eur J Clin Nutr, 63 (2009), pp. 78-86.

9. J.E. Chavarro, J.W. Rich-Edwards, B.A. Rosner and W.C. Willett, Diet and lifestyle in the prevention of ovulatory disorder infertility. Obstet Gynecol, 110 (2007), pp. $1050-1058$.

10. J.W. Rich-Edwards, D. Spiegelman, M. Garland, E. Hertzmark, D.J. Hunter and G.A. Colditz, et al. Physical activity, body mass index, and ovulatory disorder infertility. Epidemiology, 13 (2002), pp. 184-190.

11. M. Vujkovic, J.H. de Vries, J. Lindemans, N.S. Macklon, P.J. van der Spek and E.A. Steegers, et al. The preconception Mediterranean dietary pattern in couples undergoing in vitro fertilization/intracytoplasmic sperm injection treatment increases the chance of pregnancy. Fertil Steril, 94 (2010), pp. 2096-2101.

12. F. Sofi, R. Abbate, G.F. Gensini and A. Casini, Accruing evidence on benefits of adherence to the Mediterranean diet on health: an updated systematic review and meta-analysis. Am J Clin Nutr, 92 (2010), pp. 1189-1196.

13. J.J. Beunza, E. Toledo, F.B. Hu, M. Bes-Rastrollo, M. Serrano-Martínez and A. Sánchez-Villegas, et al. Adherence to the Mediterranean diet, long-term weight change, and incident overweight or obesity: the Seguimiento Universidad de Navarra (SUN) cohort. Am J Clin Nutr, 92 (2010), pp. 1484-1493.

14. M.Á. Martínez-González, Cdl Fuente-Arrillaga, J.M. Nunez-Cordoba, F.J. BasterraGortari, J.J. Beunza and Z. Vazquez, et al. Adherence to Mediterranean diet and risk of developing diabetes: prospective cohort study. BMJ, 336 (2008), pp. 1348-1351.

15. M. Segui-Gomez, C. de la Fuente, Z. Vazquez, J. de Irala and M.A. MartinezGonzalez, Cohort profile: the 'Seguimiento Universidad de Navarra' (SUN) study. Int J Epidemiol, 35 (2006), pp. 1417-1422.

16. J.M. Martin-Moreno, P. Boyle, L. Gorgojo, P. Maisonneuve, J.C. FernandezRodriguez and S. Salvini, et al. Development and validation of a food frequency questionnaire in Spain. Int J Epidemiol, 22 (1993), pp. 512-519. 
17. J.D. Fernandez-Ballart, J.L. Pinol, I. Zazpe, D. Corella, P. Carrasco and E. Toledo, et al. Relative validity of a semi-quantitative food-frequency questionnaire in an elderly Mediterranean population of Spain. Br J Nutr, 103 (2010), pp. 1808-1816.

18. J. Mataix Verdú, Tabla de composición de alimentos, (4th ed), Universidad de Granada, Granada (2003).

19. O. Moreiras, Á Carbajal, L. Cabrera and C. Cuadrado, Tablas de composición de alimentos, (12th ed), Pirámide, Madrid (2009).

20. A. Sanchez-Villegas, M. Delgado-Rodriguez, M.A. Martinez-Gonzalez and J. De Irala-Estevez, Gender, age, socio-demographic and lifestyle factors associated with major dietary patterns in the Spanish Project SUN (Seguimiento Universidad de Navarra). Eur J Clin Nutr, 57 (2003), pp. 285-292.

21. A. Sanchez-Villegas, E. Toledo, M. Bes-Rastrollo, J.M. Martin-Moreno, A. Tortosa and M.A. Martinez-Gonzalez, Association between dietary and beverage consumption patterns in the SUN (Seguimiento Universidad de Navarra) cohort study. Public Health Nutr, 12 (2009), pp. 351-358.

22. M. Bes-Rastrollo, J.R. Perez Valdivieso, A. Sánchez-Villegas, A. Alonso and M.A. Martinez-Gonzalez, Validacion del peso e indice de masa corporal auto-declarados de los participantes de una cohorte de graduados universitarios. Rev Esp Obes, 3 (2005), pp. 183-189.

23. M.A. Martinez-Gonzalez, C. Lopez-Fontana, J.J. Varo, A. Sanchez-Villegas and J.A. Martinez, Validation of the Spanish version of the physical activity questionnaire used in the Nurses' Health Study and the Health Professionals' Follow-up Study. Public Health Nutr, 8 (2005), pp. 920-927.

24. B.E. Ainsworth, W.L. Haskell, M.C. Whitt, M.L. Irwin, A.M. Swartz and S.J. Strath, et al. Compendium of physical activities: an update of activity codes and MET intensities. Med Sci Sports Exerc, 32 (2000), pp. S498-S504.

25. W.C. Willett, Nutritional epidemiology, (2nd ed), Oxford University Press, New York (1998).

26. Y. Benjamini and Y. Hochberg, Controlling the false discovery rate: a practical and powerful approach to multiple testing. J R Statist Soc B, 57 (1995), pp. 289-300.

27. S. Chatterjee and A.S. Hadi, Regression analysis by example, (4th ed), John Wiley \& Sons, New York (2006).

28. I. Cetin, C. Berti and S. Calabrese, Role of micronutrients in the periconceptional period. Hum Reprod Update, 16 (2010), pp. 80-95.

29. J.E. Chavarro, J.W. Rich-Edwards, B.A. Rosner and W.C. Willett, Use of multivitamins, intake of B vitamins, and risk of ovulatory infertility. Fertil Steril, 89 (2008), pp. 668-676.

30. F.B. Hu, E.B. Rimm, M.J. Stampfer, A. Ascherio, D. Spiegelman and W.C. Willett, Prospective study of major dietary patterns and risk of coronary heart disease in men. Am J Clin Nutr, 72 (2000), pp. 912-921.

31. P. Guallar-Castillon, F. Rodriguez-Artalejo, M.J. Tormo, M.J. Sanchez, L. Rodriguez and J.R. Quiros, et al. Major dietary patterns and risk of coronary heart disease in middle-aged persons from a Mediterranean country: the EPIC-Spain cohort study. Nutr Metab Cardiovasc Dis, (2010 Aug 11) [Epub ahead of print.].

32. A. Alonso, J.J. Beunza, M. Delgado-Rodriguez and M.A. Martinez-Gonzalez, Validation of self reported diagnosis of hypertension in a cohort of university graduates in Spain. BMC Public Health, 5 (2005), p. 94.

33. A. Sanchez-Villegas, J. Schlatter, F. Ortuno, F. Lahortiga, J. Pla and S. Benito, et al. Validity of a self-reported diagnosis of depression among participants in a cohort 
study using the Structured Clinical Interview for DSM-IV (SCID-I). BMC Psychiatry, 8 (2008), p. 43.

34. Fernandez-Montero A, Beunza JJ, Bes-Rastrollo M, Barrio MT, de la FuenteArrillaga C, Moreno-Galarraga L, et al. [Validity of self-reported metabolic syndrome components in a cohort study]. Gac Sanit 2011;25:303-7.. 


\section{Tables}

Table 1. Baseline characteristics of the 485 cases with difficulty getting pregnant and the 1,670 controls in the SUN Project (1999-2007).

\begin{tabular}{|c|c|c|}
\hline Baseline characteristic & Cases $(n=485)$ & Matched controls $(n=1,669)$ \\
\hline Age (y) & $31.3(4.4)$ & $33.1(5.3)$ \\
\hline Body mass index $\left(\mathrm{kg} / \mathrm{m}^{2}\right)$ & $21.6(2.7)$ & $22.1(2.9)$ \\
\hline Children (n) & $0.2(0.5)$ & $1.2(1.0)$ \\
\hline \multicolumn{3}{|l|}{ Smoking (\%) } \\
\hline Past smokers & 24.3 & 26.5 \\
\hline Current smokers & 24.3 & 23.2 \\
\hline Physical activity (METs, h/wk) & $21.1(18.9)$ & $19.7(17.1)$ \\
\hline Total energy intake (kcal/d) & $2279(567)$ & $2356(552)$ \\
\hline Alcohol intake $(\mathrm{g} / \mathrm{d})$ & $4.2(6.0)$ & $3.1(4.6)$ \\
\hline Coffee consumption (servings per day) & $1.2(1.2)$ & $1.2(1.2)$ \\
\hline Total fat intake (\% energy intake) & $37.5(6.6)$ & $37.9(6.2)$ \\
\hline SFA & $12.8(3.0)$ & $12.9(3.0)$ \\
\hline MUFA & $16.1(3.7)$ & $16.3(3.6)$ \\
\hline PUFA & $5.2(1.7)$ & $5.2(1.6)$ \\
\hline $\mathrm{tFA}$ & $0.4(0.2)$ & $0.4(0.2)$ \\
\hline Iron intake $(\mathrm{mg} / \mathrm{d})$ & $16.0(5.0)$ & $17.0(5.0)$ \\
\hline Plant protein $(\mathrm{g} / \mathrm{d})$ & $29.0(7.0)$ & $29.0(7.0)$ \\
\hline Animal protein $(\mathrm{g} / \mathrm{d})$ & $74.0(19.0)$ & $76.0(18.0)$ \\
\hline Dietary fiber (g/d) & $27.0(10.0)$ & $26.0(10.0)$ \\
\hline Vitamin supplements consumption (\%) & 20.4 & 24.3 \\
\hline
\end{tabular}


Table 2. Factor loadings ${ }^{\mathrm{a}}$ for the two main dietary patterns identified with principal component analysis in the SUN Project (1999-2007).

\begin{tabular}{|c|c|c|c|}
\hline Food group & $\begin{array}{l}\text { Daily intake (g/d), } \\
\text { mean (SD) }\end{array}$ & $\begin{array}{l}\text { Factor } 1 \\
\text { (Western type) }\end{array}$ & $\begin{array}{l}\text { Factor } 2 \\
\text { (Mediterranean type) }\end{array}$ \\
\hline $\begin{array}{l}\text { Unprocessed red } \\
\text { meat }\end{array}$ & $75(43)$ & 0.55 & \\
\hline Processed meat & $45(29)$ & 0.52 & \\
\hline Fast food & $22(17)$ & 0.49 & \\
\hline $\begin{array}{l}\text { Whole-fat dairy } \\
\text { products }\end{array}$ & 207 (199) & 0.36 & \\
\hline Commercial bakery & $14(20)$ & 0.36 & \\
\hline Potatoes & $51(43)$ & 0.34 & \\
\hline Eggs & $23(16)$ & 0.33 & \\
\hline Refined grains & $78(54)$ & 0.32 & \\
\hline Sauces & $3(4)$ & 0.32 & \\
\hline Processed meals & $23(30)$ & 0.31 & \\
\hline $\begin{array}{l}\text { Sugar-sweetened } \\
\text { soda }\end{array}$ & $39(70)$ & 0.30 & \\
\hline Vegetables & $547(316)$ & - & 0.65 \\
\hline Fish & $96(60)$ & - & 0.52 \\
\hline Fruits & $350(290)$ & - & 0.50 \\
\hline Poultry & $48(32)$ & - & 0.44 \\
\hline $\begin{array}{l}\text { Low-fat dairy } \\
\text { products }\end{array}$ & $255(247)$ & - & 0.41 \\
\hline Olive oil & $17(14)$ & - & 0.35 \\
\hline
\end{tabular}

${ }^{a}$ Varimax rotated factors are displayed. Factor loadings with an absolute value $<0.3$ were omitted for simplicity. 
Table 3. Odds ratio (95\% confidence intervals) for presenting with difficulty getting pregnant according to quartiles of the a posteriori-defined Western-type dietary pattern.

\begin{tabular}{llllll}
\hline Parameter & Q1 & Q2 & Q3 & Q4 & $\begin{array}{l}\text { P value for } \\
\text { trend }\end{array}$ \\
\hline No. of events & 137 & 126 & 116 & 106 & \\
Matched OR & 1 & $0.94(0.73-$ & $0.86(0.67-$ & $0.83(0.64-$ & .12 \\
& $($ ref.) & $1.20)$ & $1.11)$ & $1.08)$ & \\
Multivariable & 1 & $0.95(0.74-$ & $0.88(0.67-$ & $0.91(0.66-$ & .45 \\
model 1 & (ref.) & $1.23)$ & $1.16)$ & $1.24)$ & \\
Multivariable & 1 & $0.99(0.76-$ & $0.94(0.69-$ & $0.98(0.67-$ & .85 \\
model 2 & (ref.) & $1.29)$ & $1.27)$ & $1.44)$ & \\
\hline
\end{tabular}

Note: $\mathrm{Q}=$ quartile; $\mathrm{OR}=$ odds ratio; ref. $=$ referent. Multivariable model 1: adjusted for body mass index $\left(<25,25\right.$ to $\left.<30, \geq 30 \mathrm{~kg} / \mathrm{m}^{2}\right)$, smoking (never, past, current), alcohol consumption (g/d), total energy intake, vitamin supplements (yes/no). Multivariable model 2: additionally adjusted for intake of plant proteins $(\mathrm{g} / \mathrm{d})$, intake of animal proteins $(\mathrm{g} / \mathrm{d})$, intake of trans fat $(\mathrm{g} / \mathrm{d})$, and intake of fiber $(\mathrm{g} / \mathrm{d})$.

Table 4. Odds ratio ( $95 \%$ confidence interval) for presenting with difficulty getting pregnant according to quartiles of the a posteriori-defined Mediterranean-type dietary pattern.

\begin{tabular}{|c|c|c|c|c|c|}
\hline Parameter & Q1 & Q2 & Q3 & Q4 & $\begin{array}{l}P \text { value for } \\
\text { trend }\end{array}$ \\
\hline No. of events & 141 & 134 & 116 & 94 & \\
\hline Matched OR & $\begin{array}{l}1 \\
\text { (ref.) }\end{array}$ & $\begin{array}{l}1.05(0.83- \\
1.34)\end{array}$ & $\begin{array}{l}0.87(0.68- \\
1.11)\end{array}$ & $\begin{array}{l}0.68(0.52- \\
0.89)\end{array}$ & .002 \\
\hline $\begin{array}{l}\text { Multivariable } \\
\text { model } 1\end{array}$ & $\begin{array}{l}1 \\
\text { (ref.) }\end{array}$ & $\begin{array}{l}1.07(0.84- \\
1.37)\end{array}$ & $\begin{array}{l}0.88(0.67- \\
1.14)\end{array}$ & $\begin{array}{l}0.74(0.55- \\
1.00)\end{array}$ & .03 \\
\hline $\begin{array}{l}\text { Multivariable } \\
\text { model } 2\end{array}$ & $\begin{array}{l}1 \\
\text { (ref.) }\end{array}$ & $\begin{array}{l}1.01(0.78- \\
1.32)\end{array}$ & $\begin{array}{l}0.77(0.56- \\
1.06)\end{array}$ & $\begin{array}{l}0.56(0.35- \\
0.90)\end{array}$ & .01 \\
\hline
\end{tabular}

Note: Abbreviations as in Table 3. Multivariable model 1: adjusted for body mass index $\left(<25,25\right.$ to $\left.<30, \geq 30 \mathrm{~kg} / \mathrm{m}^{2}\right)$, smoking (never, past, current), alcohol consumption (g/d), total energy intake, vitamin supplements (yes/no). Multivariable model 2: additionally adjusted for intake of plant proteins $(\mathrm{g} / \mathrm{d})$, intake of animal proteins $(\mathrm{g} / \mathrm{d})$, intake of trans fat $(\mathrm{g} / \mathrm{d})$, and intake of fiber $(\mathrm{g} / \mathrm{d})$. 